\title{
Article \\ Effect of a Compound Energy Field with Temperature and Ultrasonic Vibration on the Material Properties and Bending Process of TC2 Titanium Alloy
}

\author{
Tiejun Gao ${ }^{1, *}$, Kaifeng Wang ${ }^{1}$, Zhiyuan Ling ${ }^{2}$ and Zhongjin Wang ${ }^{3}$ \\ 1 College of Aerospace Engineering, Shenyang Aerospace University, Shenyang 110136, China; \\ kaifeng_wang@126.com \\ 2 China Hangfa Dongan Engine Co., Ltd., Harbin 150066, China; zhiyuan_ling@163.com \\ 3 School of Materials Science and Engineering, Harbin Institute of Technology, Harbin 150001, China; \\ wangzj@hit.edu.cn \\ * Correspondence: tiejun_gao@163.com
}

Citation: Gao, T.; Wang, K.; Ling, Z.; Wang, Z. Effect of a Compound Energy Field with Temperature and Ultrasonic Vibration on the Material Properties and Bending Process of TC2 Titanium Alloy. Materials 2021, 14, 7192. https://doi.org/10.3390/ ma14237192

Academic Editor: Tomasz Czujko

Received: 12 October 2021

Accepted: 23 November 2021

Published: 25 November 2021

Publisher's Note: MDPI stays neutral with regard to jurisdictional claims in published maps and institutional affiliations.

Copyright: (c) 2021 by the authors. Licensee MDPI, Basel, Switzerland. This article is an open access article distributed under the terms and conditions of the Creative Commons Attribution (CC BY) license (https:/ / creativecommons.org/licenses/by/ $4.0 /)$.

\begin{abstract}
Due to the low formability and forming quality of titanium alloy, the forming process of a compound energy field (CEF) with temperature and ultrasonic vibration was proposed. Tensile tests were carried out to investigate the effect of the CEF on the true stress-strain curve, yield strength, elastic modulus, and other mechanical properties of the TC2 titanium alloy. Bending tests assisted by CEF were also performed to investigate the effect of different parameters of the CEF on bending force, spring-back, bending fillet radius, and microstructure of TC2 titanium. The results demonstrate that compared to the process under a single-temperature field, the CEF can reduce yield strength, elastic modulus, bending force, bending fillet, and the spring-back angle, which shows that the CEF can further increase the high-temperature softening effect of TC2 titanium. Furthermore, this effect becomes more remarkable when ultrasonic vibration energy increases. As a result, the formability of titanium alloy can be improved.
\end{abstract}

Keywords: compound energy field with temperature and ultrasonic vibration; TC2 titanium alloy; mechanical properties; bending properties; microstructure

\section{Introduction}

With the continuous improvement of modern aircraft requirements for operational performance and safety performance, airframe structure materials have evolved from the original stage of wood and cloth to the new stage of aluminum alloys, titanium alloys, superalloys, composite materials, and other materials over the past 100 years. In the process, the material requirements and the function requirements mutually prompt each other. Titanium alloys have numerous advantages over other metal materials, including low density, high strength, high- and low-temperature resistance, superior corrosion resistance, and good compatibility with composite materials [1-5]. As a result, titanium alloys play an irreplaceable role compared to other metals.

Since the 1950s, when titanium alloys were initially utilized in aircraft fuselages, the use of titanium alloys in aircraft and engines has increasingly grown. For example, the C-5 transport aircraft, which entered service in 1970, used 5\% titanium alloy, and the C-17 transport aircraft, which entered service in 1992, used 10\% titanium alloy. In addition, titanium alloy is used at a rate of $26 \%$ and $41 \%$ in the B2 strategic bomber and the F22 fighter plane, respectively.

According to published data, using titanium alloy instead of aluminum alloy increases the heat resistance temperature of an aircraft's surface from $200{ }^{\circ} \mathrm{C}$ to $400{ }^{\circ} \mathrm{C}$ [6,7]. Utilizing titanium alloy instead of stainless steel also reduces an engine's weight by $40-50 \%$ [8]. As a result, titanium alloy has become one of the most popular materials in modern aircraft design. 
In addition to having outstanding properties, titanium alloys have high strength, low elastic modulus, and low elongation [9], and are considered to be hard-to-deform materials. It has become a big challenge to form components with complicated forms using traditional methods. As a result, thermoforming is currently the most-used forming process. Due to the softening effect caused by high temperature, forming resistance decreases and formability improves when the sheet is heated to a particular temperature (usually over $500{ }^{\circ} \mathrm{C}$; the superplastic state should surpass $900^{\circ} \mathrm{C}$ ) [10-16].

Zhu et al. studied the V-shape bending tests of TC4 titanium. They discovered that when the temperature exceeded $500{ }^{\circ} \mathrm{C}$, spring-back was significantly reduced [17]. Guang et al. investigated the forming limit of TC4 titanium. The best temperature for forming is between 550 and $700{ }^{\circ} \mathrm{C}$ [18]. Lang et al. conducted drawing tests and discovered that when the temperature was raised to $600{ }^{\circ} \mathrm{C}$, formability improved considerably [19].

Ultrasonic vibration-assisted forming is a process in which ultrasonic vibration with a certain direction and energy is applied to a specimen or mold to improve formability. As early as 1955, Blaha et al. carried out ultrasonic vibration-assisted tensile tests on single-crystal zinc. It was observed that the flow stress reduced with the superposition of ultrasonic vibrations. This phenomenon is called the "softening effect" (Blaha effect), which was the earliest description of the effect of ultrasonic vibration on the plasticforming process of metal. Langenecke et al. [20] used single-crystal zinc to conduct a tensile test assisted by ultrasonic vibration in 1966. The results revealed that ultrasonic vibration causes a softening effect, which is similar to thermal softening caused by high temperatures [21]. As investigation of ultrasonic vibration-assisted forming moves forward, it may be discovered that ultrasonic vibration not only makes the material's forming force [22,23] and the friction coefficient between the mold and the specimen lower [24], but also enhances the material's forming performance and quality [25-29]. In particular, the power of the ultrasonic generator capacity has improved in recent years; ultrasonic vibration energy can now be employed in a considerably larger range of applications. Ultrasonic vibration-assisted forming has been used in the processes of blanking, deep drawing, bending, and bulging for metals such as steel, aluminum alloys, magnesium alloys, and titanium alloys. For small or micro-sized parts, ultrasonic vibration-assisted forming has unique advantages over other processes [30,31].

According to the above findings, heating or applying ultrasonic vibration to a specimen can increase its formability. As a result, if an ultrasonic vibration energy field is introduced into the titanium alloy-forming process at a specific temperature to combine the temperature field and ultrasonic vibration, the superposition of the thermal-softening effect of high temperature and the "softening effect" caused by ultrasonic vibration may further improve the formability and quality of the titanium alloy. Thus, this paper clarifies the effect of the CEF on the bending properties of titanium by analyzing the true stressstrain curve, yield strength, elastic modulus, bending force, spring-back, and bending fillet radius.

\section{Bending Process Analysis}

The geometric shape and stress distribution in the bending process of the sheet are shown in Figure 1. The initial elastic deformation and elastic-plastic deformation give way to plastic deformation as drawing deformation increases. However, due to the material's elastoplastic deformation characteristic, spring-back occurs after the removal of external loads in both the elastoplastic- and plastic-deforming stages, causing a large change in the bending fillet radius, angle, and other size characteristics, which affects dimension precision and performance [32]. 


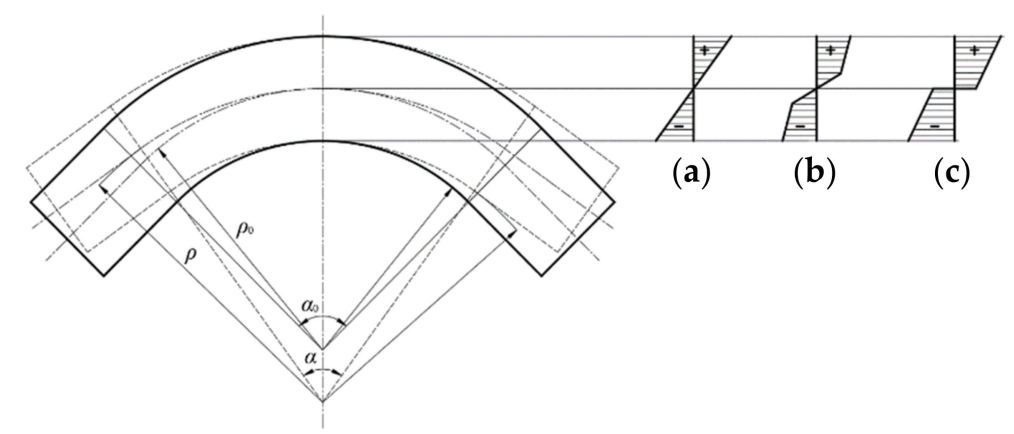

Figure 1. Stress distribution and spring-back during sheet bending: (a) elastic bending, (b) elasticplastic bending, (c) plastic bending.

The variation in the bending angle before and after spring-back can be expressed as:

$$
\Delta \alpha=\alpha_{0}-\alpha
$$

where $\Delta \alpha$ is the variation in the angle of the specimen; $\alpha$ is the bending angle of the sheet after spring-back; and $\alpha_{0}$ is the bending angle of the sheet before spring-back.

The variation of the bending fillet radius of the specimen before and after spring-back can be expressed as:

$$
\Delta \rho=\rho-\rho_{0}
$$

where $\Delta \rho$ is the variation in the bending fillet radius of the specimen before and after spring-back; $\rho$ is the bending fillet radius of the plate after spring-back; and $\rho_{0}$ is the bending fillet radius of the sheet before spring-back.

Assuming that the length of the neutral layer is constant, the relationship between the angle and the fillet radius can be expressed as [33]:

$$
\alpha_{0}=\frac{\rho}{\rho_{0}} A
$$

The relationship between the variation in angle and the variation in the bending fillet radius can be expressed as:

$$
\Delta \rho=\frac{\rho_{0}}{\alpha} \Delta \alpha
$$

However, the spring-back of the sheet is related not only to the geometric shape but also to the yield strength $\sigma_{s}$, the material hardening exponent $n$, the elastic modulus $E$, and other parameters of material performance. However, the parameters are changed under the CEF. Thus, a systematic study of the effect of the CEF on the parameters is required.

\section{Experimental Materials and Scheme}

\subsection{Experimental Material}

The material used for the tests was TC2 titanium alloy. TC2 titanium alloy is a mediumstrength neat- $\alpha$-type titanium alloy with a microstructure of coexisting $\alpha$ and $\beta$ phases. Under high temperatures, TC2 titanium alloy usually works at $350{ }^{\circ} \mathrm{C}$ for a long time and at $750{ }^{\circ} \mathrm{C}$ for a short time. It is mainly used in the manufacture of aircraft wings, stabilizers, flaps, and other stressed components. The chemical composition is shown in Table 1 [34], and the thickness is $1.0 \mathrm{~mm}$. The temperature of thermal forming is usually $550-600{ }^{\circ} \mathrm{C}$ [35].

Table 1. Chemical composition of TC2 titanium alloy (\%).

\begin{tabular}{cccccccc}
\hline Fe & $\mathbf{C}$ & $\mathbf{N}$ & $\mathbf{H}$ & $\mathbf{O}$ & $\mathbf{A l}$ & $\mathbf{M n}$ & Ti \\
\hline$\leq 0.30$ & $\leq 0.08$ & $\leq 0.05$ & $\leq 0.012$ & $\leq 0.15$ & $\leq 3.5-5.0$ & $\leq 0.8-2.0$ & balance \\
\hline
\end{tabular}




\subsection{Experimental Principle and Scheme}

As shown in Figure 2, the experimental principle of the forming assisted by the $\mathrm{CEF}$ is to control temperature by the temperature control system (A area) and applying ultrasonic vibration by the ultrasonic vibration-assisted device (B area). The compound of temperature and ultrasonic vibration is realized by the superposition and interaction of temperature and ultrasonic vibration.

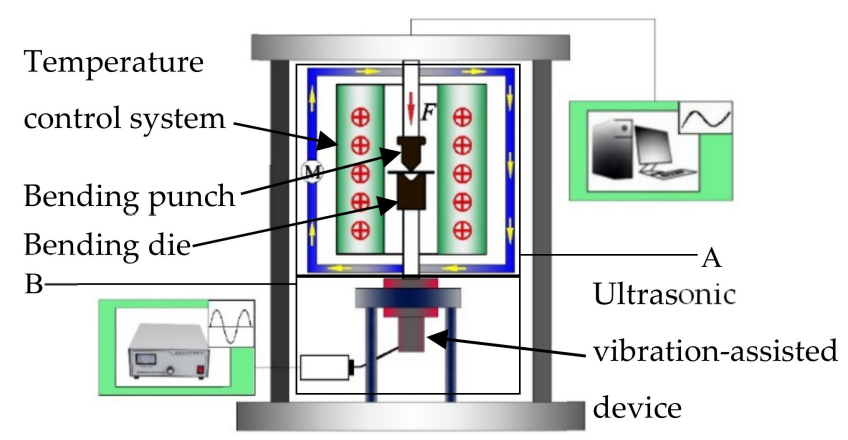

Figure 2. Compound energy field with temperature and ultrasonic vibration-assisted bending experimental device.

The tensile tests of the TC2 titanium alloy sheet under different CEF parameters were first carried out to clarify the effect of the CEF on the properties of titanium alloy. Then, the $90^{\circ} \mathrm{V}$-shaped mold was selected for the bending experiment under different CEFs, combining the results of the tensile tests to analyze the effect of the CEF on the bending properties of titanium alloy. In the tests, the rate of both tensile tests and bending tests was $0.003 \mathrm{~s}^{-1}$. The experimental temperatures were $20^{\circ} \mathrm{C}, 500^{\circ} \mathrm{C}, 550^{\circ} \mathrm{C}$, and $600{ }^{\circ} \mathrm{C}$, due to the thermal stability and current investigation of titanium alloy [34]. Ultrasonic vibration with power of $1.0 \mathrm{~kW}, 1.2 \mathrm{~kW}$, and $1.4 \mathrm{~kW}$, with frequency of $20 \mathrm{kHz}$, was applied throughout the process of tensile tests and bending tests. In order to validate the consistency of results, each test was carried out six times.

The specimens were first heated to the required temperature and the temperature was held for $10 \mathrm{~min}$ to make sure that the tests were carried out in isothermal conditions, in ae furnace controlled by the GW-1200 Electrical Furnace Controller, produced by FangRui Technology Co., Ltd., Changchun, China. Then, the tensile tests and bending tests were carried out.

\section{Experimental Results and Analysis}

\subsection{Tensile Results and Analysis}

Figure 3 shows the true stress-strain curve of TC2 under the CEF and the specimenthe size of the tensile specimen is shown in Figure 3a. When there is no ultrasonic vibration $(0 \mathrm{~kW})$ as is the case under a single-temperature field, as the temperature increases the strength of TC2 continues to decrease, and the overall stress-strain curve shifts downward. When the temperature is below $550^{\circ} \mathrm{C}$, work-hardening is the main characteristic of the true stress-strain curve. When the temperature reaches $600^{\circ} \mathrm{C}$, the high-temperature softening effect appears. Compared with the single-temperature field, when the deformation enters the plastic deformation stage, the stress-strain curve of TC2 is further reduced under the $\mathrm{CEF}$, indicating that the softening effect has occurred and is maintained during the vibration. In addition, the softening effect increased with an increase in ultrasonic power. Hung et al. performed hot upsetting tests and the results indicated that ultrasonic vibration could considerably reduce the forces during forming [36]. Hung et. al. concluded that the mechanisms of increased temperature and energy absorption of dislocation could affect the material property and cause a reduction in forming forces [37]. The regulations presented in these literatures are in accordance with those observed in our tests. 


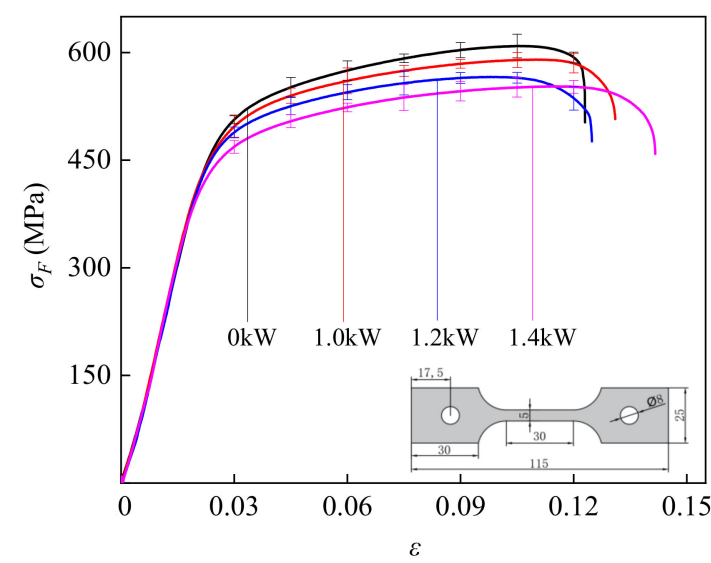

(a)

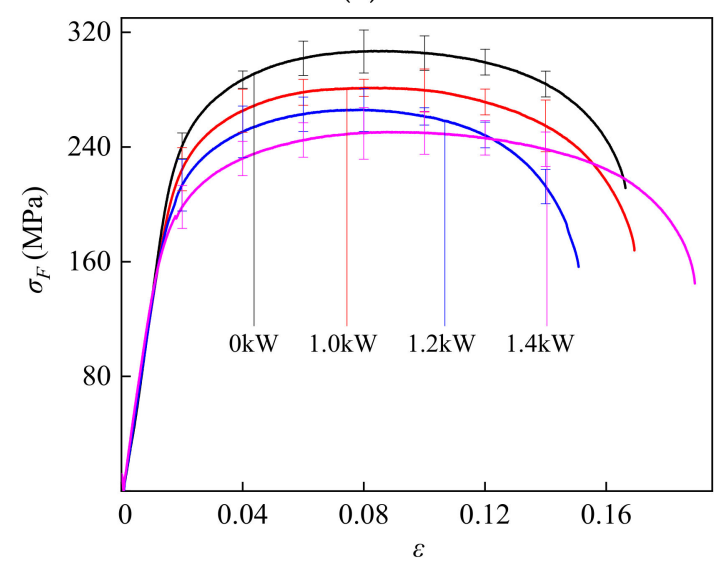

(c)

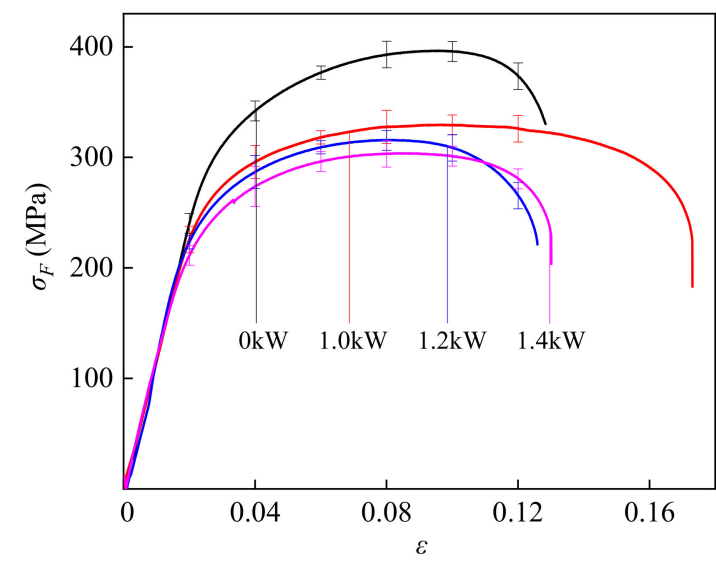

(b)

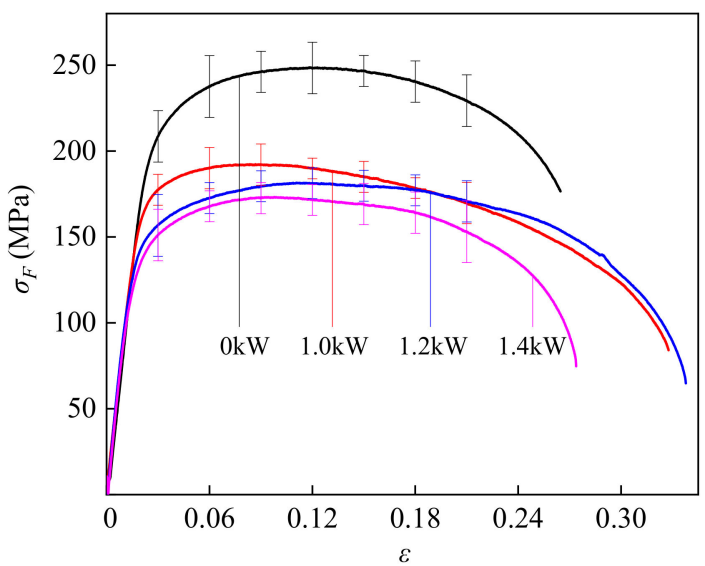

(d)

Figure 3. True stress-strain curve of TC2 under the CEF: (a) $20^{\circ} \mathrm{C}$; (b) $500{ }^{\circ} \mathrm{C} ;$ (c) $550{ }^{\circ} \mathrm{C}$; (d) $600{ }^{\circ} \mathrm{C}$.

On the one hand, because ultrasonic vibration helps to increase the capability of surmounting obstacle/dislocation arrays, this leads to a decrease in the dislocation multiplication rate but an increase in the probability of dislocation annihilation [23]. On the other hand, another part of the high-frequency vibration energy will be superimposed with the temperature field, resulting in a reduction in stress. In addition, as shown in Figure 3, the ultimate strain of TC2 fluctuates with the increase in ultrasonic power, caused by the interaction among microstructures [38].

Figures 4-6 show the values of $\sigma_{s}, n$, and $E$ of TC2 titanium alloy under different CEFs. The measurements of $\sigma_{s}$ were all within the $95 \%$ confidence interval of the confidence level. The values of $n$ and $E$ were calculated with the true stress-strain curve based on the Swift model $[39,40]$. It can be seen from the figures that the values of $\sigma_{s}, E$, and $n$ further reduce when the temperature increases. Compared with the single-temperature field, the reduction in the values of $\sigma_{s}$ and $n$ were larger under the CEF, and the higher the temperature, the greater the reduction in the values of $\sigma_{s}$ and $n$. However, the effect of the CEF on the value of $E$ was not as obvious as it was on the values of $\sigma_{s}$ and $n$. 


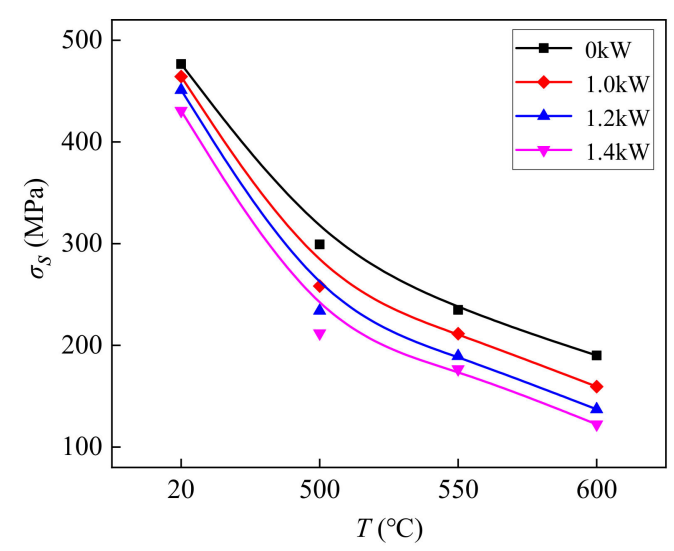

Figure 4. The effect of the CEF on the value of $\sigma_{s}$.

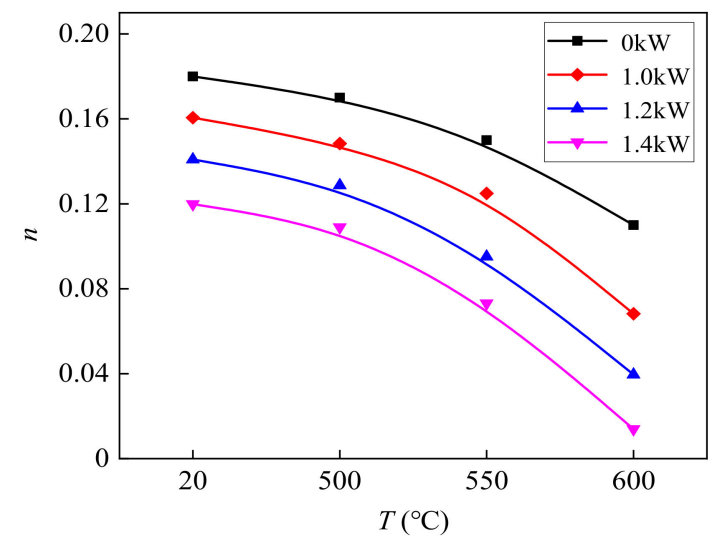

Figure 5. The effect of the CEF on the value of $n$.

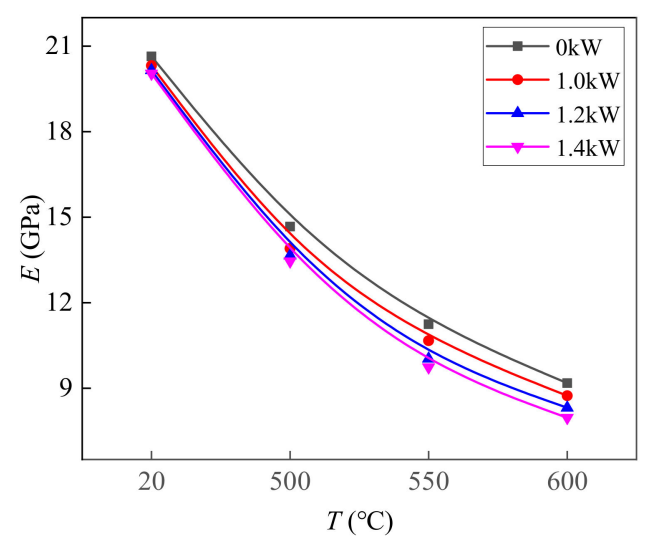

Figure 6. The effect of the CEF on the value of $E$.

\subsection{Bending Results and Analysis}

A $90^{\circ} \mathrm{V}$-shaped mold was selected for the bending tests. Figure 7 shows the bending force-punch stroke curve ( $F$ and, $S$, respectively) under different CEFs and specimens. The size of the bending specimen was $20 \mathrm{~mm} \times 50 \mathrm{~mm}$. The TC2 titanium alloy is mostly elastically deformed in the early stages of bending deformation, and the bending force grows rapidly with the punch going down. When the punch stroke exceeds $3 \mathrm{~mm}$, the deformation of material changes from elastic deformation to plastic deformation, and the rate of increase in bending force slows down. After the stroke of the punch reaches $9 \mathrm{~mm}$, the bending part fits the mold, which causes the bending force to increase when the deformation continues. At the same time, it can be seen from Figure 6 that the reduction in the bending force-punch stroke under the CEF is larger than it is in the single-temperature 
field. This is because the ultrasonic energy input increases the high-temperature softening effect. Meanwhile, the instantaneous separation between the specimen and the mold reduces the hindrance to the material flow and the bending force [41].

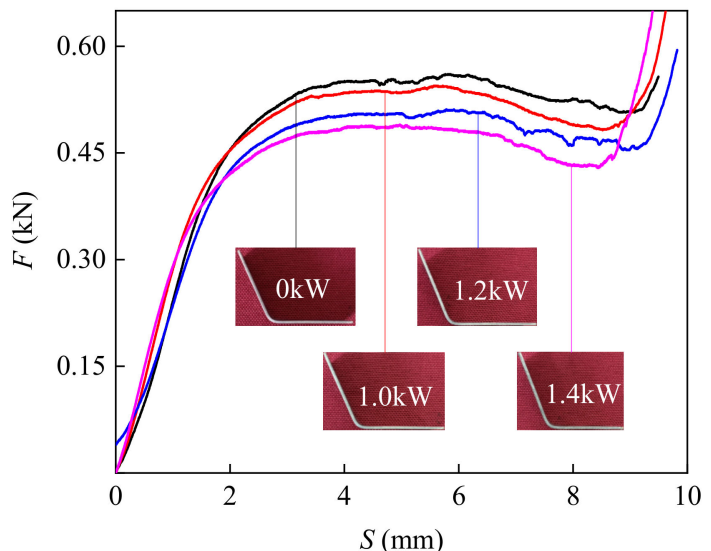

(a)

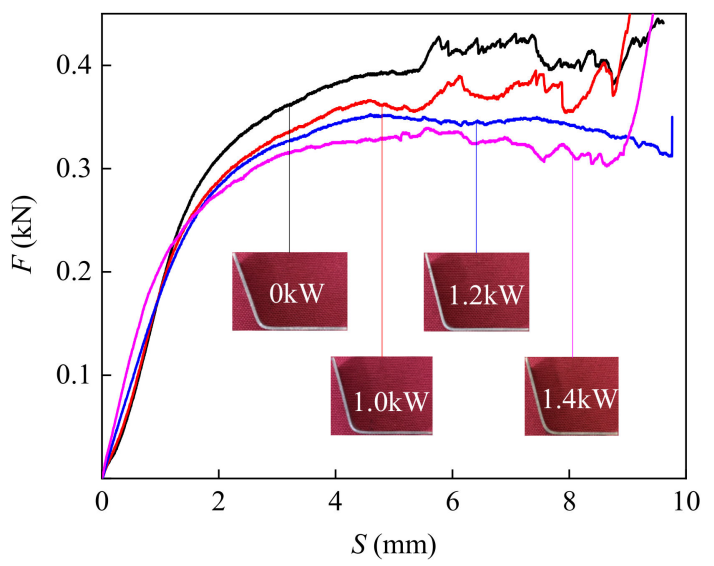

(c)

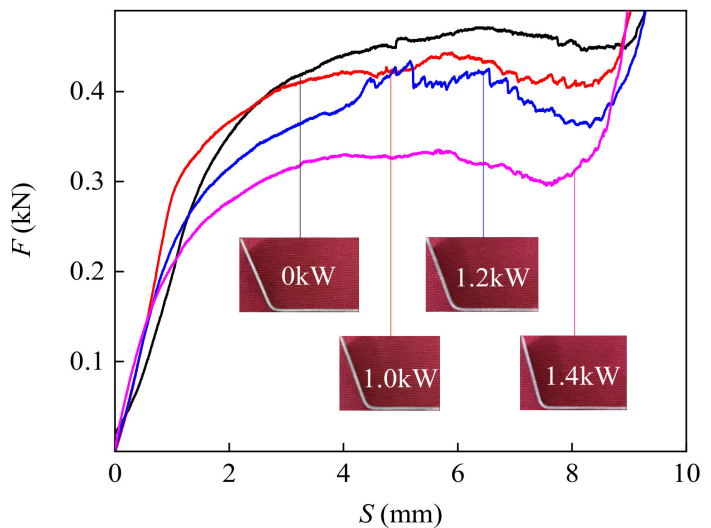

(b)

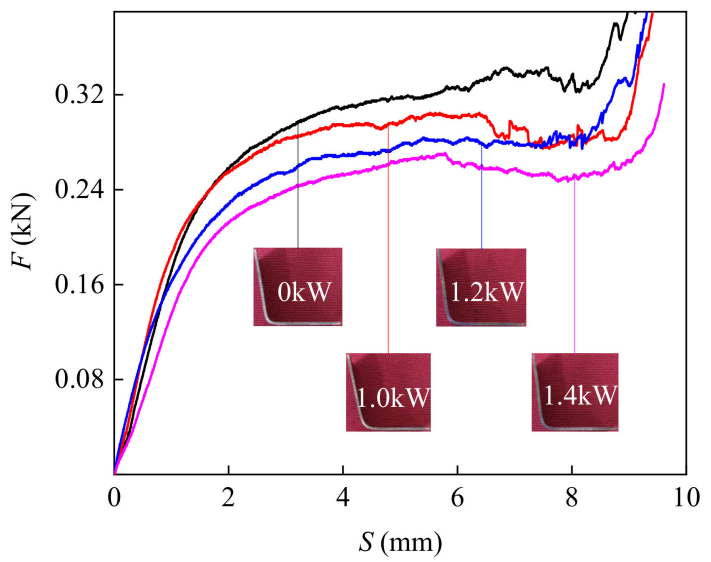

(d)

Figure 7. The bending force-punch stroke curve under different CEFs: (a) $20^{\circ} \mathrm{C}$; (b) $500{ }^{\circ} \mathrm{C}$; (c) $550{ }^{\circ} \mathrm{C}$; (d) $600{ }^{\circ} \mathrm{C}$.

Figures 8 and 9 show a comparison of spring-back and bending fillet radius under different CEF parameters, which were all within the $95 \%$ confidence interval of the confidence level. When the parameters of the $\mathrm{CEF}$ were $20^{\circ} \mathrm{C} / 0 \mathrm{~kW}, 500{ }^{\circ} \mathrm{C} / 0 \mathrm{~kW}, 550{ }^{\circ} \mathrm{C} / 0 \mathrm{~kW}$, and $600{ }^{\circ} \mathrm{C} / 0 \mathrm{~kW}$ (the single-temperature field), the spring-back was $25.97^{\circ}, 19.97^{\circ}, 16.07^{\circ}$, and $13.01^{\circ}$, respectively. With the increase in temperature, the spring-back continues to decrease. When ultrasonic power was $1.0 \mathrm{~kW}$, the parameters of the $\mathrm{CEF}$ were $20^{\circ} \mathrm{C} / 1.0 \mathrm{~kW}$, $500{ }^{\circ} \mathrm{C} / 1.0 \mathrm{~kW}, 550{ }^{\circ} \mathrm{C} / 1.0 \mathrm{~kW}$, and $600{ }^{\circ} \mathrm{C} / 1.0 \mathrm{~kW}$, and the spring-back of the bending specimen was $22.87^{\circ}, 16.87^{\circ}, 12.97^{\circ}$, and $9.4^{\circ}$, respectively. The reduction was $11.9 \%, 15.5 \%$, $19.2 \%, 35.1 \%$, respectively. When ultrasonic power increased to $1.4 \mathrm{~kW}$, the parameters of the CEF were $20^{\circ} \mathrm{C} / 1.4 \mathrm{~kW}, 500{ }^{\circ} \mathrm{C} / 1.4 \mathrm{~kW}, 550{ }^{\circ} \mathrm{C} / 1.4 \mathrm{~kW}$, and $600{ }^{\circ} \mathrm{C} / 1.4 \mathrm{~kW}$ and the spring-back of the banding specimen was $19.89^{\circ}, 13.87^{\circ}, 9.97^{\circ}$, and $7.4^{\circ}$, respectively. Compared with the single-temperature field, the reduction was $23.41 \%, 30.54 \%, 37.95 \%$, and $45.18 \%$, respectively. When compared, the effect of inhibiting spring-back of the TC2 titanium alloy under the CEF with $550^{\circ} \mathrm{C} / 1.0 \mathrm{~kW}$ was consistent with the effect under the single-temperature field at $600^{\circ} \mathrm{C}$. Moreover, the effect of inhibiting the spring-back of the TC2 titanium alloy under the $\mathrm{CEF}$ with $550{ }^{\circ} \mathrm{C} / 1.4 \mathrm{~kW}$ was consistent with the effect under the single-temperature field at $600{ }^{\circ} \mathrm{C}$. It can be seen that the effect of the $\mathrm{CEF}$ on the bending fillet radius is similar to the spring-back shown in the comparison between Figures 8 and 9. Therefore, under the same temperature conditions, the combination of 
the temperature field and ultrasonic vibration can further improve the bending properties and the quality of the bending specimen of the TC2 titanium alloy. Alternatively, for the same bending specimen of the TC2 titanium alloy, the combination of the temperature field and ultrasonic vibration can lower the forming temperature, which is helpful in reducing production costs.

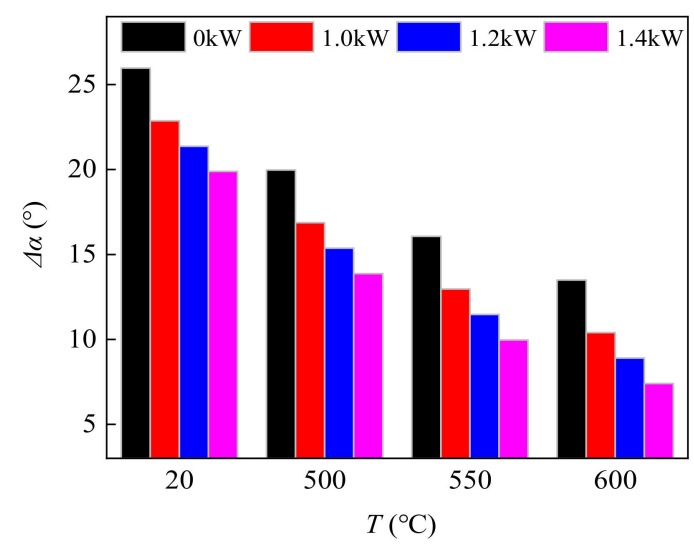

Figure 8. The spring-backs of TC2 bending parts under the CEF.

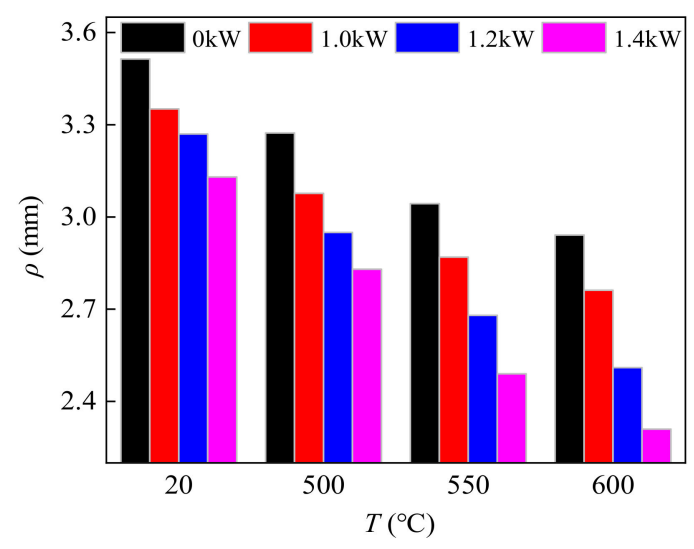

Figure 9. The fillet radius of TC2 bending parts under the CEF.

\subsection{Effect of the CEF on Microstructure}

To further explore the mechanism of the CEF on the bending properties of the TC2 titanium alloy, the samples were embedded in mosaic powder, then polished to achieve the requirement of no scratches. After corrosion for about $90 \mathrm{~s}$ by Kroll's Reagent, which consisted of $2 \% \mathrm{HF}, 6 \% \mathrm{HNO}_{3}$, and $92 \% \mathrm{H}_{2} \mathrm{O}$, the samples were observed by the TESCAN MIRA3 scanning microscope (SEM), produced by TESCAN CHINA, Ltd. Then the grain size was manually measured using the intercept method according to ASTM E112 [42]. The average grain size was obtained by measuring three different areas in the sample.

Figure 10 shows the metallographic structure of the TC2 titanium alloy under the CEF. It can be seen that the metallographic structure changes with the change of the parameters of the CEF. Compared with the single-temperature field, the average grain size is larger under the CEF. For example, under the single-temperature field, when the temperatures are $500{ }^{\circ} \mathrm{C}$ and $600{ }^{\circ} \mathrm{C}$, the average grain sizes are about $10.4 \mu \mathrm{m}$ and $10.8 \mu \mathrm{m}$, respectively. However, when ultrasonic power is $1.0 \mathrm{~kW}$, the average grain sizes are about $11.5 \mu \mathrm{m}$ and $12.3 \mu \mathrm{m}$ under temperatures of $500{ }^{\circ} \mathrm{C}$ and $600{ }^{\circ} \mathrm{C}$, respectively. The results further demonstrate that ultrasonic vibration can improve the high-temperature softening effect, in accordance with the results obtained by Wang [23] and Huang [26]. 


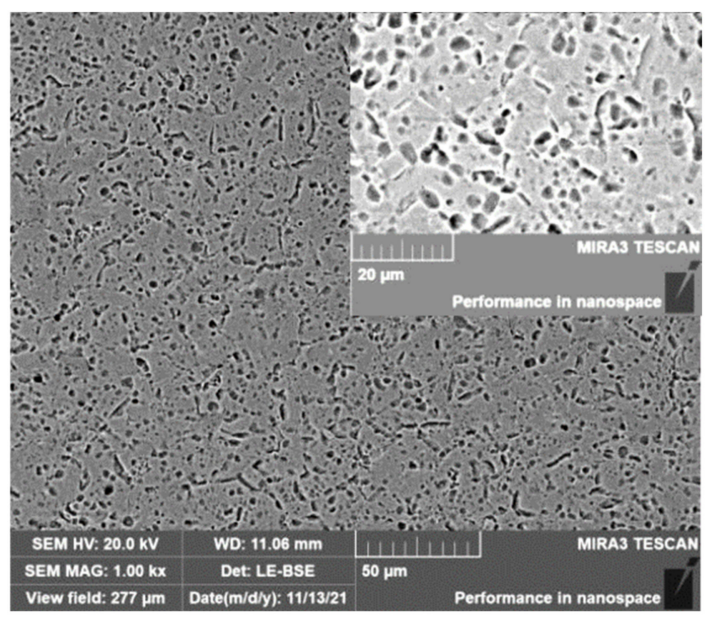

(a)

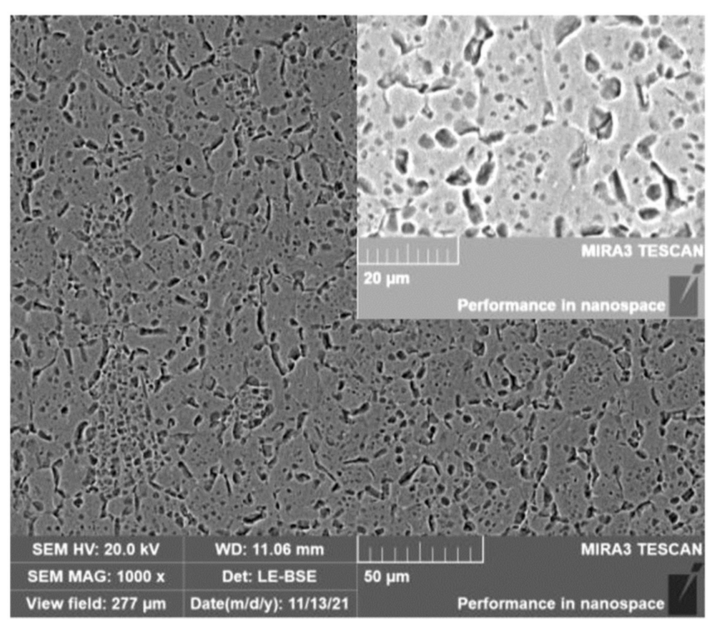

(c)

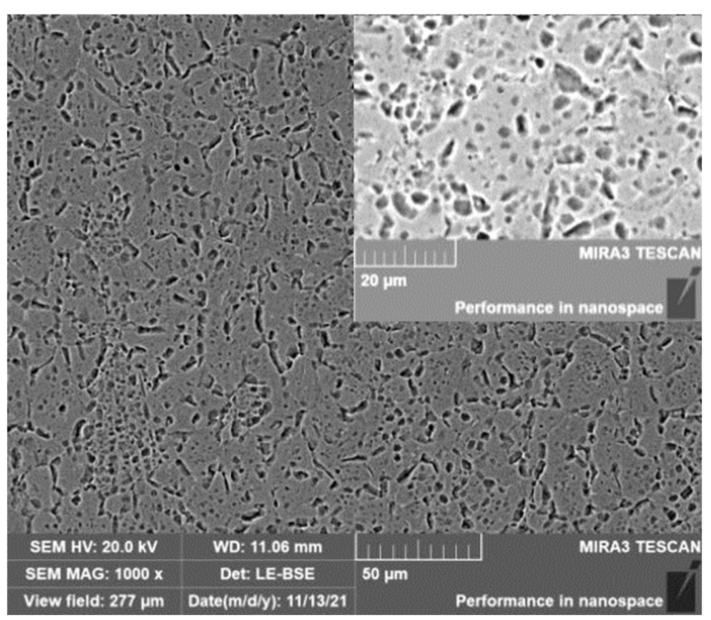

(b)

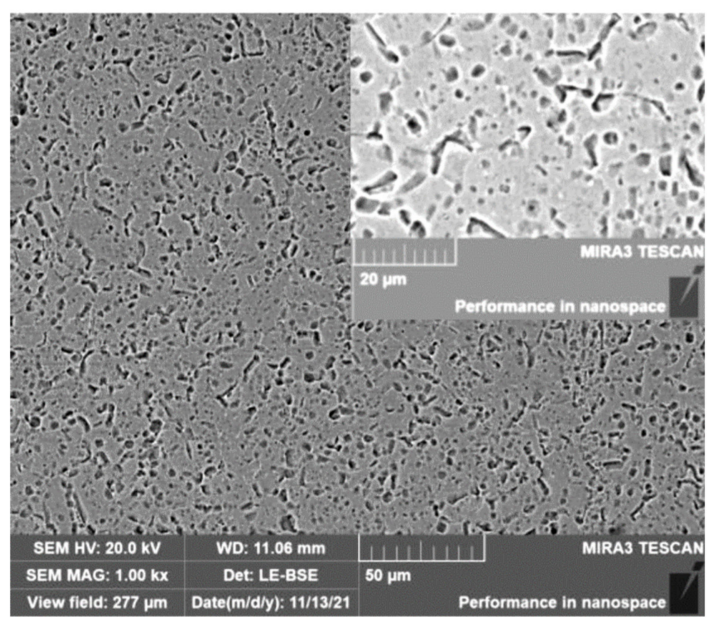

(d)

Figure 10. The structure of the TC2 titanium alloy under the CEF: (a) $500{ }^{\circ} \mathrm{C} / 0 \mathrm{~kW}$; (b) $500{ }^{\circ} \mathrm{C} / 1.0 \mathrm{~kW}$; (c) $600{ }^{\circ} \mathrm{C} / 0 \mathrm{~kW}$; (d) $600{ }^{\circ} \mathrm{C} / 1.0 \mathrm{~kW}$.

\section{Conclusions}

1. The results of the tensile tests of TC2 under the CEF show that, compared with a single-temperature field, the strength and the material-hardening exponent decrease due to the high-temperature softening effect increased by the CEF. Therefore, the CEF can effectively enhance the plastic formability of the sheet, and the effect increases with the increase in ultrasonic energy.

2. The results of the bending tests for TC2 under the CEF show that, compared with a single-temperature field, the CEF can reduce the bending force and spring-back of the TC2 parts and effectively increase the quality of bending parts.

3. Microstructure observation of the TC2 titanium alloy shows that grain size increases under the effect of ultrasonic vibration, which further increases the high-temperature softening effect.

4. The combination of the temperature field and ultrasonic vibration can further improve the mechanical properties and bending properties of titanium, which is helpful in improving the quality and properties of titanium alloy parts. 
Author Contributions: Conceptualization, T.G. and K.W.; methodology, T.G.; software, Z.L.; validation, T.G.; formal analysis, K.W.; investigation, K.W.; resources, T.G.; data curation, Z.L.; writingoriginal draft preparation, K.W.; writing - review and editing, K.W.; visualization, K.W.; supervision, Z.W.; project administration, Z.W.; funding acquisition, T.G. All authors have read and agreed to the published version of the manuscript.

Funding: This research was funded (1) the National Natural Science Foundation of China (No. 52075347, 51575364); (2) the Liaoning Basic Scientific Research Projects in University (No. LJKZ0192).

Institutional Review Board Statement: Not applicable.

Informed Consent Statement: Not applicable.

Data Availability Statement: Not applicable.

Acknowledgments: This study was financially supported by the National Natural Science Foundation of China (No. 52075347, 51575364) and the Liaoning Basic Scientific Research Projects in University (No. LJKZ0192).

Conflicts of Interest: The authors declare no conflict of interest.

\section{References}

1. Pan, S.; Fu, M.; Liu, H.; Chen, Y.; Yi, D. In Situ Observation of the Tensile Deformation and Fracture Behavior of Ti-5Al-5Mo-5V1Cr-1Fe Alloy with Different Microstructures. Materials 2021, 14, 5794. [CrossRef] [PubMed]

2. Wang, B.; Cheng, L.; Li, D. Experimental Study on Forged TC4 Titanium Alloy Fatigue Properties under Three-Point Bending and Life Prediction. Materials 2021, 14, 5329. [CrossRef] [PubMed]

3. Bao, X.; Cheng, L.; Ding, J.; Chen, X.; Lu, K.; Cui, W. The Effect of Microstructure and Axial Tension on Three-Point Bending Fatigue Behavior of TC4 in High Cycle and Very High Cycle Regimes. Materials 2020, 13, 68. [CrossRef] [PubMed]

4. Zhang, D.; Liu, N.; Chen, Y.; Zhang, G.; Tian, J.; Kong, F.; Xiao, S.; Sun, J. Microstructure Evolution and Mechanical Properties of PM-Ti43A19V0.3Y Alloy. Materials 2020, 13, 198. [CrossRef]

5. Gupta, N.K.; Somani, N.; Prakash, C.; Singh, R.; Walia, A.S.; Singh, S.; Pruncu, C.I. Revealing the WEDM Process Parameters for the Machining of Pure and Heat-Treated Titanium (Ti-6Al-4V) Alloy. Materials 2021, 14, 2292. [CrossRef]

6. Abby, L. Current Status of Titanium Alloys for Aircrafts Application; The International Titanium Association: Las Vegas, NV, USA, 2013.

7. Vanderhasten, M.; Rabet, L.; Verlinden, B. Ti-6Al-4V: Deformation map and modelisation of tensile behaviour. Mater. Des. 2008, 29, 1090-1098. [CrossRef]

8. Lang, L.H.; Liu, B.S.; Zeng, Y.S. Titanium Alloy Plate Forming Technology and Its Application in Aviation Industry. Aeronaut. Manuf. Technol. 2009, 10, 28-31.

9. Lü, Z.D.; Zhang, C.J.; Du, Z.X.; Han, J.C.; Zhang, S.Z.; Yang, F.; Chen, Y.Y. Relationship between microstructure and tensile properties on a near- $\beta$ titanium alloy after multidirectional forging and heat treatment. Rare Met. 2019, 38, 336-342. [CrossRef]

10. Li, X.F.; Xu, F.F.; Hu, L.; Zhu, F.H.; Chen, J. Tensile deformation behavior of coarse-grained Ti-55 titanium alloy with different hydrogen additions. Rare Met. 2021, 40, 2092-2098. [CrossRef]

11. Ashraf Imam, M. The 12th world conference on titanium presents research and applications of "wonder metal". JOM 2011, 63, 16-23. [CrossRef]

12. Ulutan, D.; Ozel, T. Machining induced surface integrity in titanium and nickel alloys: A review. Int. J. Mach. Tools Manuf. 2011, 51, 250-280. [CrossRef]

13. Wang, A.; Zhong, K.; Fakir, O.E.; Liu, J.; Sun, C.Y.; Wang, L.L.; Lin, J.G.; Dean, T.A. Springback analysis of AA5754 after hot stamping: Experiments and FE modelling. Int. J. Adv. Manuf. Technol. 2017, 89, 1339-1352. [CrossRef]

14. Simonetto, E.; Venturato, G.; Ghiotti, A.; Bruschi, S. Modelling of hot rotary draw bending for thin-walled titanium alloy tubes. Int. J. Mech. Sci. 2018, 148, 698-706. [CrossRef]

15. Yao, K.; Min, X.H.; Satoshi, E.; Tsuchiya, K. Coupling effect of deformation mode and temperature on tensile properties in TWIP type Ti-Mo alloy. Mater. Sci. Eng. A 2019, 766, 1-10. [CrossRef]

16. Thomas, P.; Matthias, G.; Marion, M. Numerical modelling approach for the temperature dependent forming behavior of Ti-6Al-4V. Matec Web Conf. 2018, 190, 1-6.

17. Zhu, Y. Research on Pulse Current-Assisted Bending Forming Law of Titanium and Titanium Alloy. Master's Thesis, Taiyuan University of Technology, Taiyuan, China, 2020.

18. Guang, K.H.; Yao, Y.F.; Wu, T.L.; Liu, B.B. Study on Forming Limit of Incremental Forming of TC4 Titanium Alloy Sheet by Electromagnetic Induction Heating. Hot Work. Technol. 2021, 50, 86-89.

19. Lang, L.H.; Liu, K.N.; Cai, G.C.; Guo, C. Numerical Research on Forming Technology of Complicated Taper-shaped Part of TC4 Titanium Alloy by Thermal Deep Drawing with Heated Media. Synth. Manuf. Technol. Complex Struct. 2013, 16, 109-112.

20. Blaha, F.; Langenecker, B. Elongation of zinc monocrystals under ultrasonic action. Die Nat. 1955, 42, 556. [CrossRef]

21. Langenecker, B. Effects of Ultrasound on Deformation Characteristics of Metals. IEEE Trans. Sonics Ultrason. 1966, 13, 1-8. [CrossRef] 
22. Wang, C.J.; Liu, Y.; Guo, B.; Shan, D.B.; Zhang, B. Acoustic softening and stress superposition in ultrasonic vibration assisted uniaxial tension of copper foil: Experiments and modeling. Mater. Des. 2016, 112, 246-253. [CrossRef]

23. Wang, X.W.; Wang, C.J.; Liu, Y.; Liu, C.; Wang, Z.L.; Guo, B.; Shan, D.B. An energy based modeling for the acoustic softening effect on the Hall-Petch behavior of pure titanium in ultrasonic vibration assisted micro-tension. Int. J. Plast. 2021, 136, 102879. [CrossRef]

24. Lin, J.; Li, J.; Liu, T.; Xie, Z.D.; Zhu, L.H.; Wang, Y.; Guan, Y.J. Investigation on ultrasonic vibration effects on plastic flow behavior of pure titanium: Constitutive modeling. J. Mater. Res. Technol. 2020, 9, 4978-4993. [CrossRef]

25. Ren, Z.J.; Lai, F.Q.; Qu, S.G.; Zhang, Y.L.; Li, X.Q.; Yang, C. Effect of ultrasonic surface rolling on surface layer properties and fretting wear properties of titanium alloy Ti5Al4Mo6V2Nb1Fe. News Sci. 2020, 389, 125612. [CrossRef]

26. Huang, Y.M.; Wu, Y.S.; Huang, J.Y. The influence of ultrasonic vibration-assisted micro-deep drawing process. Int. J. Adv. Manuf. Technol. 2014, 71, 1455-1461. [CrossRef]

27. Schinke, B.; Malmberg, T. Dynamic tensile tests with superimposed ultrasonic oscillations for stainless steel type 321 at room temperature. North-Holl. 1987, 100, 281-296. [CrossRef]

28. Shalvandi, M.; Hojjat, Y.; Abdullah, A.; Asadi, H. Influence of ultrasonic stress relief on stainless steel 316 specimens: A comparison with thermal stress relief. Mater. Des. 2013, 46, 713-723. [CrossRef]

29. Xu, L.H.; Lei, Y.L.; Zhang, H.O.; Zhang, Z.C.; Sheng, Y.C.; Han, G.C. Research on the Micro-Extrusion Process of Copper T2 with Different Ultrasonic Vibration Modes. Metals 2019, 9, 1209. [CrossRef]

30. Zha, C.L.; Chen, W. Theories and experiments on effects of acoustic energy field in micro-square cup drawing. Int. J. Adv. Manuf. Technol. 2019, 104, 4791-4802. [CrossRef]

31. Wu, X.; Li, J.J.; Zheng, Z.Z.; Chen, X.D. Research and application progress of metal plastic forming mechanism under vibration field. J. Plast. Eng. 2015, 22, 1-7.

32. Ma, W.P.; Wang, B.Y.; Xiao, W.C.; Yang, X.M.; Kang, Y. Springback analysis of 6016 aluminum alloy sheet in hot V-shape stamping. J. Cent. South Univ. 2019, 26, 524-535. [CrossRef]

33. Yang, X.M.; Dang, L.M.; Wang, Y.Q.; Zhou, J.; Wang, B.Y. Springback prediction of TC4 titanium alloy V-bending under hot stamping condition. J. Cent. South Univ. 2020, 27, 2578-2591. [CrossRef]

34. Xie, W.; Wei, D.; Chen, B.; Zhang, X. Preliminary study on "striated Groove" on the surface of TC2 titanium alloy sheet. World Nonferrous Met. 2021, 15, 118-119.

35. Yang, W.J.; Li, D.S.; Li, X.Q.; Li, Y. Hot forming process optimization of a complex titanium alloy part with numerical simulation method. J. Plast. Eng. 2009, 16, 42-46.

36. Hung, J.C.; Hung, C.G. The influence of ultrasonic-vibration on hot upsetting of aluminum alloy. Ultrasonics 2005, 43, 692-698. [CrossRef]

37. Hung, J.C.; Lin, C.C. Investigations on the material property changes of ultrasonic-vibration assisted aluminum alloy upsetting. Mater. Des. 2013, 45, 412-420. [CrossRef]

38. Zheng, J.X.; Du, X.W.; Cheng, J. On the special behavior of ductile metal subjected to ultrasonic action. Acta Aeronaut. Et Astronaut. Sin. 2000, 4, 334-337.

39. Tong, P.Y.; Zhang, P.; Wang, Y.J.; Han, Y.B.; Liu, B.; Guo, Q.Q. Tensile Properties and Stress-strain Curve Fitting of Aluminum Alloy Sheets Commonly Used for Aviation. Tool Eng. 2019, 53, 41-46.

40. Shao, W. Research on Hot Forming Properties of TC4 High Strength Titanium Alloy Sheet. Master's Thesis, Shanghai University of Engineering Science, Shanghai, China, 2020.

41. Zhang, H.D.; Deng, L.; Wang, X.Y.; Jin, J.S. Research Progress on Mechanism and Application of Vibration Assisted Plastic Forming. Aeronaut. Manuf. Technol. 2020, 63, 22-31.

42. ASTM E112. Standard Test Methods for Determining Average Grain Size; American Society for Testing and Materials: New York, NY, USA, 2012. 